\title{
Establishing Systematic Modular Courses for Key Teaching Competencies of Teachers in Hsinchu City
}

\author{
Yuan-Chuan Cheng ${ }^{1}$, Yin-Che Chen ${ }^{2}$, Woei-Min Chiang ${ }^{3} \&$ Chuan-Lien Yang ${ }^{3}$ \\ ${ }^{1}$ Department of Education and Learning Technology, National Hsinchu University of Education, Hsinchu, \\ Taiwan \\ ${ }^{2}$ Graduate Institute of Human Resource and eLearning Technology, National Hsinchu University of Education, \\ Hsinchu, Taiwan \\ ${ }^{3}$ Hsinchu City Government, Department of Education, Hsinchu, Taiwan \\ Correspondence: Yin-Che Chen, Graduate Institute of Human Resource and eLearning Technology, National \\ Hsinchu University of Education, No. 521, Nanda Rd., Hsinchu City 30014, Taiwan. Tel: 886-3-521-3132. \\ E-mail: yinchechen@mail.nhcue.edu.tw
}

\author{
Received: November 28, 2014 Accepted: January 6, 2015 Online Published: April 27, 2015 \\ doi:10.5539/ies.v8n5p21 \\ URL: http://dx.doi.org/10.5539/ies.v8n5p21
}

\begin{abstract}
The evolution of the Internet, trends in mobile device usage, and changes in the perceptions of city leaders and residents have gradually transformed cities into smart cities. Through a literature review, survey analysis, and focus group interview, this study explored the educational vision and consensus in developing Smart Hsinchu, and analyzed course requirements for key teaching competencies and contents of digital teaching abilities, all of which facilitate achieving the educational vision. Finally, this study established systemized modular courses for key teaching competencies and relevant strategies to promote these courses.
\end{abstract}

Keywords: smart city, digital teaching ability, modular courses

\section{Background and Objectives}

\subsection{Introduce the Problem}

Developments involving the Internet, mobile device usage, and changes in the perceptions of city leaders and residents have contributed to the emergence of smart cities, which are aimed at promoting resident satisfaction with urban governance, with particular regard to the areas of energy, traffic, education, water resource management, health, and industry. A smart city can be broadly defined as the diffusion of urban public services through the use of information technology to provide convenience to businesses and citizens. However, smart cities develop differently according to the regional characteristics, business patterns, and temporality of goal formulations of each city (Intelligent City of Hsinchu of Information Service Network, 2014).

The Hsinchu Intelligent City Project Office was founded in March 2012 to establish an innovative e-platform as an integrated system for managing various municipal topics (e.g., energy conservation, carbon reduction, urban governance, intelligent life technology, and ecological communities) to enhance the quality of life of citizens, for which it was listed as a Smart2 1 community and named the Intelligent Community of the Year by the Intelligent Community Forum in 2013 (Hsinchu City Government, 2014). In 2013, the Hsinchu Municipal Government envisioned "intelligence, lifestyles of health and sustainability" as an urban development goal, with the objective of implementing the concepts of e-government, e-community, and e-life.

To realize its vision of a smart city, the Hsinchu Municipal Government proposed a development plan for primary and secondary (K-9) school digital cloud learning systems (e-schoolbags) to promote the e-community concept. Since 2011, the local government has promoted the acclaimed cloud education program in Ching Tsao $\mathrm{Hu}$ Elementary School, providing senior students with tablet computers as instructional equipment to enable them to obtain course materials through a cloud-based e-learning platform. The local government intends to expand this program to all public elementary schools to close the digital divide among schoolchildren by providing them with early access to e-learning while cultivating their creativity through the use of advanced technologies (Intelligent City of Hsinchu of Information Service Network, 2014). 
All teachers in Hsinchu strongly believe in the fundamentals of all things. In addition, schools in Hsinchu have been dedicated to creating a loving school environment, enhancing teacher capability and student conduct, and improving learning efficiency, which the Hsinchu City Education Department (HCED) has incorporated into six action dimensions: cooperation, competence enhancement, deliberative sharing, key leadership, feature exhibition, and performance evaluation as a basis for developing and implementing education policies in Hsinchu City (Hsinchu City Government, 2013). To promote these six dimensions and address the needs of educational institutions, the HCED actively promoted a 3-Year teaching enhancement program from 2012 to 2014, cohering consensus on teaching enhancement and realizing the vision of effective teaching, adaptive growth, community-wide learning, sustainability, and excellence.

Based on this background and in accordance with the educational vision for Smart Hsinchu and the objective of improving teachers' competency, the goals of this study are summarized as follows:

1) Explore the educational vision and highlights of Smart Hsinchu.

2) Analyze the key competency course requirements for Hsinchu teachers to achieve the educational vision.

3) Draft a key teaching competency curriculum for K-9 teachers according to the promoted educational vision.

4) Design course modules centered on key teaching competency.

\section{Research Methods}

\subsection{Literature Analysis}

This study reviewed the literature to collect data pertaining to teachers' professional development, modular courses, key teaching competencies, teacher training courses, smart cities, international education, science education, exploration education, environmental education, reading education, digital technology, and digital teaching ability worldwide. By combining these data with data on Hsinchu's axial municipal development and featured school development, this study provides a reference for questionnaire design, data analysis, and modular course planning, as well as details on establishing a systematic modular course focusing on key teaching competencies.

\subsection{Questionnaire Analysis}

Data were collected using a self-developed structured questionnaire that was prepared based on the findings of focus group interviews, relevant global education policies, and professional developments in teaching. The questionnaire comprised the following two sections: (a) personal information, including age, sex, education level, years of teaching experience, field of teaching, school of service; and (b) table of course requirements (including education highlights and topics) for teachers' key teaching competencies.

This study focused on teachers of private and public K-9 schools in Hsinchu. According to 2012 statistics reported by the Department of Statistics, Ministry of Education, there are 40 private and public K-9 schools in Hsinchu, with a total of 3,001 teachers. Table 1 lists the number of K-9 schools and teachers in each administrative area. The schools were divided into Levels A, B, and C according to the numbers of classes. We distributed 21, 17, and 13 questionnaires to each respective level; the questionnaires were completed by principals, teachers serving concurrently as directors or chiefs, counselors or subject instructors, and parents (Table 2). In this study, a total of 794 questionnaires were distributed. After eliminating invalid questionnaires, this study used a statistical method (i.e., frequency distribution, percentages, mean values, and standard deviations) to explore the teachers' needs pertaining to modular courses on key teaching competencies

Table 1. K-9 schools and teachers in Hsinchu

\begin{tabular}{lcccc}
\hline & \multicolumn{2}{c}{ Primary Schools } & \multicolumn{2}{c}{ Secondary Schools } \\
\cline { 2 - 5 } & Number of Schools & Number of Teachers & Number of Schools & Number of Teachers \\
\hline East District & 15 & 1085 & 7 & 659 \\
North District & 7 & 550 & 3 & 277 \\
Hsian Shang District & 10 & 324 & 3 & 106 \\
Total & 27 & 1959 & 13 & 1042 \\
\hline
\end{tabular}


Table 2. Questionnaire distribution and respondent data

\begin{tabular}{lccc}
\hline & Level A & Level B & Level C \\
\hline Respondents & 21 & 17 & 13 \\
Principals & 1 & 1 & 1 \\
Teachers serving concurrently as directors or chiefs & 4 & 4 & 4 \\
Counselors or subject instructors & 8 & 6 & 4 \\
Parents & 8 & 6 & 4
\end{tabular}

Note. Primary Level A: $\geq 40$ classes, Level B: 12-39 classes, Level C: $\leq 12$ classes; Secondary Level A: $\geq 24$ classes, Level B: 12-24 classes, Level C: $\leq 12$ classes.

\subsection{Focus Group Interview}

This study invited HCED administrators, the Hsinchu National Education Counseling Group (HSECG), administrators and teachers from K-9 schools in Hsinchu, scholars specializing in the professional development of teachers, and parents to participate in a focus group interview regarding the educational visions and highlights of Hsinchu and the required course modules for teachers' key competencies.

This study planned to invite experts from the National Hsinchu University of Education (NHUE), the HCED administrators, HSECG, National Academy of Educational Research (NAER) scholars, the K-9 school administrators and teachers in Hsinchu, scholars with expertise in teacher professional development, and parents to form a focus group. Twelve symposiums were held, and the group discussed the systematic course modules for key teaching competencies in Hsinchu. Subsequently, we integrated the questionnaire results, drafted the content of teachers' key competencies, revised the training programs formulated in this study, modified the learning objectives in the courses to include basic digital teaching ability, and planned the curriculum for the administrators and teachers.

\section{Research Results}

\subsection{Educational Visions and Highlights}

Among the 794 distributed questionnaires, 691 were recovered, 170 of which were eliminated because the respondents did not answer the first question regarding the image of Hsinchu City (Question 1). The final sample comprised 521 completed questionnaires, yielding a recovery rate of $72.93 \%$. The first question was analyzed using the sequencing analysis method, and the remaining questions were analyzed according to the frequency distribution.

The analysis results indicated that the top choices regarding the image of Hsinchu City's education vision were in the order of smart city, science city, cultural city, and healthy city. The key dimensions of education that a smart city should develop are in the order of science education, reading education, multicultural education, international education, exploration education, and environmental education. These six areas of education cultivate students' learning abilities, including their self-awareness and development potential, active inquiry-based learning, independent thinking and problem-solving, appreciation of performance and innovation, cultural learning, and international understanding.

\subsection{Contents of K-9 Teachers' Digital Teaching Ability}

Through the discussion on the logic of course structures and literature review, the focus group scholars believed that the priority of the course modules should not be student learning objectives, but teachers' digital teaching ability (Figure 1). Moreover, the experts believed that the assessment dimensions for digital teaching ability proposed by Wang and Shen (2010) in their research titled "Developing the Indicators for the Digital Teaching Abilities of Primary and Junior High School Teachers" were suitable for the course modules. The five dimensions are: basic computer hardware and software capabilities, network resources application, the use of teaching technologies in the classroom, the management of teaching and learning at school, and information society(Shen, 2010). The use of these dimensions could ensure that the course structure and digital teaching ability are connected. Table 3 lists the five digital teaching ability dimensions and indicates how they are related to teachers' abilities. 
Table 3. Dimensions and content of K-9 teachers' digital teaching ability

\begin{tabular}{|c|c|}
\hline Dimension & Contents \\
\hline $\begin{array}{l}\text { Basic computer software and hardware } \\
\text { capabilities }\end{array}$ & $\begin{array}{l}\text { Understand how to operate hardware } \\
\text { Understand how to use software } \\
\text { Basic Internet skills }\end{array}$ \\
\hline Network resources application & $\begin{array}{l}\text { Internet information processing } \\
\text { Internet teaching skills }\end{array}$ \\
\hline $\begin{array}{l}\text { The use of teaching technologies in the } \\
\text { classroom }\end{array}$ & $\begin{array}{l}\text { Using media as an instructional aid } \\
\text { Personalized teaching technology }\end{array}$ \\
\hline $\begin{array}{l}\text { The management of teaching and learning at } \\
\text { school }\end{array}$ & $\begin{array}{l}\text { Integrate information technology into classroom management } \\
\text { Management of teaching activities } \\
\text { Develop students' ability to use information technology as a } \\
\text { learning aid }\end{array}$ \\
\hline Information society & $\begin{array}{l}\text { Information security } \\
\text { Information ethics } \\
\text { Personal and professional development } \\
\text { Other topics on the information society }\end{array}$ \\
\hline
\end{tabular}

\subsection{Course Module Structure}

Based on the literature, questionnaires, and the focus group, we conceptualized the course modules as a pyramid structure (Figure 1) with digital technology at the base. Through the training courses for teachers, Hsinchu City's educational topics, including reading education, international education, science education, exploration education, and environmental education are promoted to realize the image of the smart city. Furthermore, training programs for teachers can be systemized and modularized through the development of the smart city, thus honing teachers' skills in applying digital teaching technology, thereby fostering Hsinchu students to become skilled at active exploration and learning, appreciation of performance and innovation, cultural learning and international understanding, understanding of self and potential and development, independent thinking, and problem-solving. 


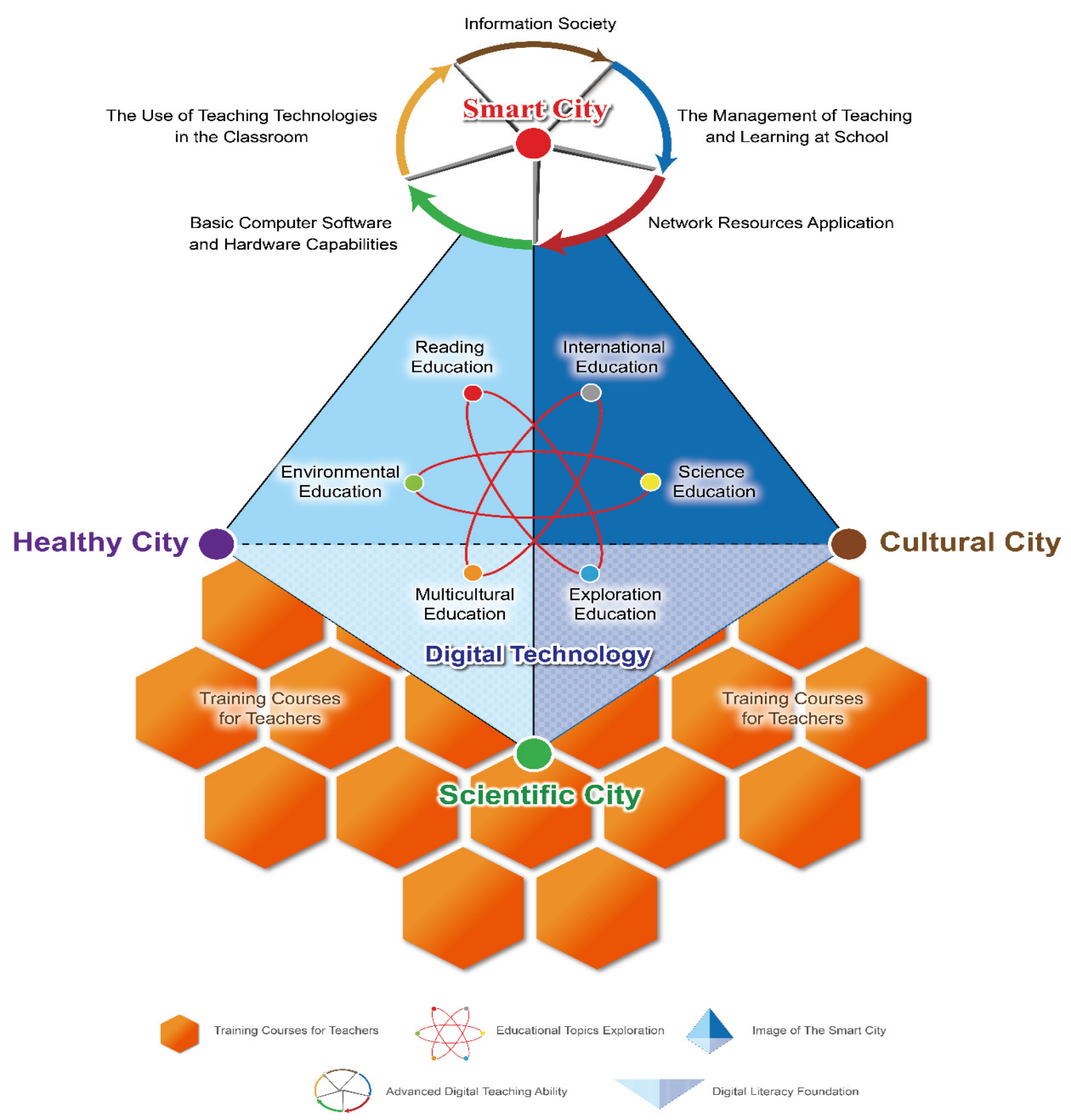

Figure 1. Structure of the course modules for key teaching competencies 


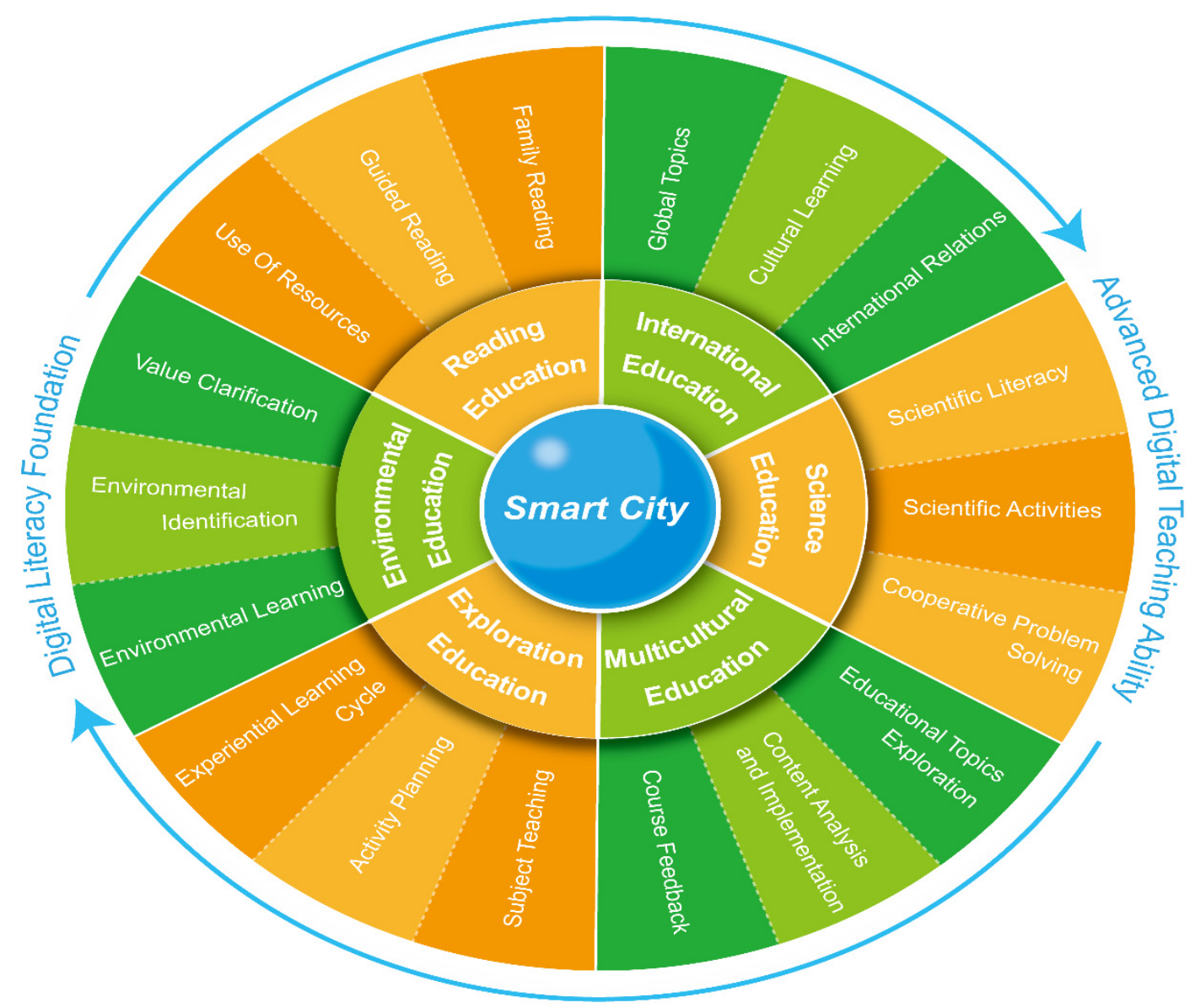

Figure 2. Key teaching competencies course module content

The systemized course modules for teachers' key competencies were developed according to the educational image of the smart city, including reading education, international education, science education, multicultural education, exploration education, and environmental education. The course contents of each topic (Figure 2) were established through an analysis of the literature to supplement the findings of the focus group comprising the NHUE, the HCED administrators, HNECG, teachers from Taoyuan, Hsinchu, and Miaoli districts who were familiar with course development, and NAER scholars.

\subsubsection{Reading Education: Use of Resources, Guided Reading, and Family Reading}

a. Use of resources.

To efficiently integrate book resources, the Ministry of Education established the National Reading Promotion and Library Collection Management System, which provides free access to a Cloud-based book management system for schools. Furthermore, the system is aimed at facilitating the construction of long-term reading databases with the objective of maximizing the function of the K-9 book resources in Taiwan through effective knowledge management practices ( $\mathrm{Wu}, 2010)$. In addition, the Ministry of Education has promoted various reading activities at schools: weekly library reading courses encouraging students to practice self-reading, education on using library resources while each class is taking library reading courses, establishing "Monthly Book" through official school websites and announcing updates in libraries on a monthly basis, organizing daily reading activities in libraries, publishing "Weekly Article," promoting reading education passports, publishing quarterly school magazines, theme reading based on educational topics, publishing reading education results for each semester, conducting research on reading education for teachers, and establishing library committees and staff book clubs (Ou, 2013).

b. Guided reading.

Reciprocal teaching is an instructional activity that emphasizes teacher-student and peer-peer dialogue, which is 
effectively a cognitive apprenticeship and is in alignment with the concept of scaffolding (Vygotsky, 1962), which is aimed at encouraging students to actively construct meaning from text. These strategies can improve the students' reading comprehension abilities and teach them to monitor their learning and thoughts. Teachers and students repeatedly work through a cycle of predicting, questioning, clarifying, and summarizing until they finish reading an entire article (Chen, 2009).

c. Family reading.

Family reading refers to parents and children reading together, which is also known as shared reading (Chang \& Liu, 2011). By engaging in family reading at home, parents foster their children's knowledge and promote positive parent-child interactions (Y. T. Chen \& Y. C. Chen, 2008). In family reading, the conversation between parents and their children is more constructive because it focuses on learning, discussing, communicating, and comprehending the text. Conversations are generally related to specific topics aimed at encouraging the children to ask questions, describe the story, and predict what is going to happen next. Moreover, Ratner and Bruner (1978) found that through long-term family reading activities, preschool children develop a routine of reading books; furthermore, if parents frequently ask their children about their thoughts and feelings toward the characters, then the children are more likely to comprehend and describe stories from the characters' perspective when reading and narrating them in the future (Chou \& Chang, 2008).

\subsubsection{International Education: Global Topics, Cultural Learning, and International Relations}

a. Global topics.

The core objective of global topics courses is to foster students' global literacy, their understanding of the basic concepts pertaining to global issues, as well as their ability to analyze the complexity and relationship among global topics. Students must be instructed on how to assess and identify the international environment while maintaining a neutral position without forming rash judgments regarding sociocultural values that conflict with their own beliefs. Furthermore, students must possess civic awareness and global citizenship who are willing to propose methods for solving global issues (https://www.ietw.moe.gov.tw/GoWeb/include/index.php?Page=1-A).

A student-centered approach must be adopted for international education. Therefore, among the four strategies of course development and teaching, international exchange, internationalization of schools, and teachers' professional development promoted by Ministry of Education in 2012 for "White Paper on International Education for Primary and Secondary Schools", course development and teaching is the most critical. Currently, the Ministry of Education has prioritized planning and promoting student courses such as international (and domestic) cultural learning, international relations, and critical global topics (e.g., environmental protection, climate change, international human rights, and gender equality), and implemented international learning programs for students. These efforts are aimed at cultivating students who can demonstrate both local and international literacy (Lin, 2012).

b. Cultural studies.

Courses on cultural studies focus on teaching students to consider multiple perspectives when they encounter other cultures, and to improve their understanding of the processes involved in cultural change, including the influence of a culture's past, present, and future, as well as the role of technology, migration, and urbanization. Students must also be taught to evaluate key events and development trends in a culture, and to compare cultures based on multiple perspectives. Additionally, students must possess cross-cultural understanding and communication skills, and be able to identify similarities and differences between cultures, appreciate the values of other cultures, tolerate cultural differences, and learn to connect with people from different cultures.

c. International relations.

The core objective of the international relations courses is to foster students' abilities to analyze how personal actions affect local, national, and global communities, identify how global problems are related to local communities and nations, participate in global citizen activities, evaluate the processes of democratic actions, and conduct themselves appropriately as members of society. To solve global issues, students must also learn to tolerate problematic situations in global issues and the uncertainty of potential solutions to those problems, acquire information related to global issues by using various methods, and recognize the advantages, disadvantages, and reliability of information sources.

\subsubsection{Science Education: Scientific Literacy, Scientific Activities, and Cooperative Problem Solving}

a. Scientific literacy.

Cultivating students' scientific literacy is the core of science education, the content of which includes knowledge, 
concepts, opinions, capability, attitudes, and techniques. Science literacy is not just about mastering the content of school courses; it also emphasizes teaching students to internalize knowledge and skills to develop an attitude that enables them to manage real-life challenges. Logical reasoning and rationality apply to not only science, but also the humanities, social sciences, and real-life issues (Ye, 2011).

b. Scientific exploration.

Scientific exploration refers to the processes of investigating and solving problems. When applied to teaching, it refers to student activities aimed at developing scientific knowledge and conceptual understanding, including observing defining problems, verifying facts by using books and other data resources, comprehending extant knowledge, planning exploration activities, investigating evidence through repeated experimentation, using tools to collect, analyze, and interpret data, and presenting a conclusion (Luo \& Lin, 2012).

c. Cooperative problem-solving.

Creative problem solving (CPS) is a widely applicable approach to thinking creatively. Developed by Parnes and Meadow (1959), CPS involves applying a systematic method to investigate problems. In contrast to general problem-solving methods, CPS emphasizes diverse thinking, implying that problem solvers must use every available method to consider various alternatives before selecting or executing a solution (Wei, 2001).

Cooperative problem-solving is aimed at teaching students to solve problems by working with others and at developing their critical thinking and problem-solving skills and promoting interpersonal interaction. CPS is a student-centered method of cooperative learning for teaching students to solve problems. Dividing students into groups to work on assignments or solve problems provides an opportunity for them to work through the process of allocating tasks, working independently, discussing problems, and finding a solution.

The CPS teaching strategy proposed by Nelson is divided into three parts comprising nine stages: (1) Stages 1-4: investigate, understand, and divide the work involved in solving a problem; (2) Stages 5-6: repeatedly discuss the problem, cooperate with others to work toward a solution, and present their findings; and (3) Stages 7-9: reflect on the solution, provide feedback, and offer a conclusion. Previous research showed that using cooperative problem solving as a teaching method can enhance schoolchildren's motivation to learn, improve their learning outcomes, and cultivate their critical thinking and problem-solving skills (Chao, 2013).

3.3.4 Multicultural Education: Educational Topics Exploration, Content Analysis and Implementation, and Course Feedback

a. Educational topics exploration.

Recent probing of multicultural study topics focuses on the concept of new immigrant culture. Ho (2004) adopted critical and sociocultural literacy-oriented educational perspective to examine Taiwanese and Vietnamese women. Through reading texts commonly appearing in life, dialogues and discussion in class, and freelance and journal writing after class, she assisted students in developing their critical reflection skills and improved their understanding of multiculturalism. Lai (2007) investigated the life experiences of the children of working-class new immigrant women, which provided teachers with basic knowledge for practicing multicultural education.

b. Content analysis and implementation.

The core of this course content is to help learners expand the learning contents that facilitate their development of subjectivity. For example, when selecting and organizing instructional materials, teachers should consider the differences in the students' ability to read Mandarin, and incorporate multimedia materials (e.g., photos, videos, or music) wherever possible. To assist students in grasping the principle of the critical literacy, teachers should select stimulating media that motivates learners to express their own stories and that establishes a link to their immediate life circumstances and experience. Suitable media for cross-cultural marriages includes videos and news clips (Ho, 2004).

c. Course feedback.

An issue that is commonly encountered when implementing multicultural courses is that people must first understand the differences between themselves and other people to overcome communication barriers. Similarly, when people understand their own cultural identity, they are more able to understand the norms and values of other cultures. Regarding suitable approaches for teaching students to understand their cultural identity, Gomez recommended that teachers first share their personal experiences of hardship, confusion, achievement, and frustration to provide an opportunity for students and other teachers to listen to life stories from different perspectives; through this process, both teachers and students have an opportunity to confront their prejudices 
and develop a mutual understanding (Lai, 2007).

\subsubsection{Exploration Education: Experiential Learning Cycle, Activity Planning, Subject Teaching}

a. Experiential learning cycle.

Proposed by Kolb (YEAR), the experiential learning cycle is a typical experiential learning operation model comprising four basic links: concrete experience, reflective observation, abstract conceptualization, and action experimentation (Wang \& $\mathrm{Li}, 2008$ ). Wu, Kuo, and Chung (2007) asserted that learning cycles involve active and cooperative learning strategies that assist students to investigate, clarify, and analyze data effectively. Furthermore, they allow flexibility for students to apply their knowledge at an appropriate time, which benefits students by improving their creativity and critical thinking skills.

\section{b. Activity planning.}

To verify that experiential learning exerts a positive influence on the psychological well-being of students, Wang and Li (2008) designed eight experiential activities through theoretical experiments and studies of experiential learning cycle. The experiments were designed to assist students in adjusting their emotions, cooperating in groups, concentrating, learning to express appreciation, improving low self-esteem and self-confidence, forming good habits, exercising their imagination, and overcoming fatigue from studying. These activities were focused on helping the students to relax their bodies and minds in a relaxing yet adequately challenging situation, gain contextual experiences, better express their self-reflections and feelings regarding the situation, improve their self-awareness, and reconstruct their experience and values.

c. Subject teaching.

Ji (2009) developed a series of unit-teaching activities by using self-compiled instructional materials titled "The Program of Adventure Education Merging into Integrative Activity Learning Area in Elementary Schools." By integrating exploration education into the mixed activity learning courses for Grade 6 students, she reconstructed the students' relationships with themselves, other people, and the environment through reflection, contemplation, clarification, practice, and discussion.

\subsubsection{Environmental Education: Value Clarification, Environmental Identification, and Environmental Learning}

a. Value clarification.

Value clarification involves guiding students through the process of value-creation by engaging them in instructional activities that assist them with developing clear life values through introspection. The three strategies for guiding students through the value-clarification process are: conversation, which teaches students about clarification and reaction; writing, which requires students to list their values; and discussion, which emphasizes the designing and application of discussion activities. Teachers can apply these strategies to encourage students to deliberate on their opinions and behaviors, which enable them to evaluate various objects, events, and related consequences. Teachers must ensure that the students are provided with the opportunity and the right to make choices, because only by contemplating the consequences of the choices can they develop their own values (Yeh \& Tang, 2006).

\section{b. Environmental identification.}

Environmental identification (emotionally symbolic attachment) is the sense of attachment a person has with a particular place (i.e., a sense of belonging). Williams and Patterson (1996) believed that psychological attachment to a place can stimulate a person to demonstrate responsible environmental behavior; specifically, when a person identifies with a particular environment, they typically behave responsibly while in that environment (Chen, Jian, \& Ou, 2013).

c. Environmental learning.

Environmental learning can be practiced through an environment education center that can provide cases for students to analyze and facilities for students to learn from. By collaborating with teachers to design extracurricular activities aimed at satisfying teaching goals, environmental education centers can facilitate formal education; furthermore, if such centers host seminars or teacher-training programs, it becomes an informal education provider. Similarly, when it is used to promote environmental concepts or hold impromptu teaching, it again becomes an informal education organization (Chou \& Chiang, 2013).

\section{Promotion Strategies}

The Hsinchu government developed the systemized course modules in order to achieve the vision of the smart city and to improve teachers' digital teaching ability. Through these efforts, the government has promoted 
reading education, international education, science education, exploration education, multicultural education, and environmental education. Based on the findings of this study and the focus group, the HCED has developed the following strategies to promote the systemized modular course for key teaching competencies:

\subsection{Digital Course Module Structure}

The course modules were divided into six dimensions: reading education, international education, science education, exploratory education, multicultural education, and environmental education. Each dimension was further divided into three topics. The topics were sequentially and logically structured, and are vertically and horizontally connected to the educational issues.

Each education topic takes 7 hours to complete: 1 hour for elaborating the corresponding concepts and theories for each topic, 2 hours for comprehending and investigating the topics, and 4 hours for case implementation, analysis, and reflection. This study used online learning model for the elaboration tasks and an actual classroom model for the comprehension, investigation, and implementation tasks.

\subsection{Contents of the Educational Topics}

Based on the content of the modular course and recent training information for K-9 schools in Taiwan, this study proposed the following course modules:

1) Reading education. Four levels of PIRLS comprehension, family reading, guided reading and innovation activities, and My Class's Book Club-Using the picture book Mr Peabody's Apple.

2) International education. Unlimited Learning, Children's Park-The World of Arts and Imagination, The New Children of Taiwan-Fairy Tales in Pictures, AIESEC International Congress.

3) Science education. Scientific learning and teaching practices, Internet technology and science education, contemplation of scientific societal issues, integration of information technology in science teaching and evaluation.

4) Multicultural education. Multicultural programs and teaching, multicultural education and new-immigrant families, multiculture and arts, multicultural education for new-immigrant children.

5) Exploration education. Theory and practice of exploration education, scientific exploration education and experience, reflection and feedback.

6) Environmental education. Domestic environmental education innovative teaching, disaster prevention education, ecological arts, environmental protection art classes.

\subsection{Context of Promotion}

Prior to promoting Hsinchu's modular courses for teachers' key teaching competencies, school administrators must first comprehend (a) the smart city concept, (b) the Hsinchu municipal government and HCED's visions, ideals, policies, and promotion strategies pertaining to the smart city concept, and (c) the educational topics and contents of the modular courses. The sequence of the promotion strategies is described as follows. The municipal promotion strategy should be implemented first to explain the policy measures of the Smart Hsinchu. The school promotion strategy should then be implanted to explain the HCED's procedure for implementing the systemized modular course for key teaching competencies. Finally, the research team can explain the educational topics of the key teaching competency modules and the corresponding course content.

\subsection{Recommendations for Future Research}

Hsinchu's modular courses are a novel strategy and mechanism for cultivating and promoting teachers' digital teaching ability. We believe that the HCED must formulate a certification standard, recruit seed teachers, and establish an evaluation platform for the K-9 schools in Hsinchu according to the school size and the status of their information technology facilities for competent authorities, schools, and teachers to follow.

The HCED must formulate a certification standard for teachers' digital teaching ability, and apply such standard to new K-9 teachers in Hsinchu to reinforce a foundation for the modular courses, thereby enhancing the effectiveness of the courses.

\section{Anticipated Results}

1) Planning the modular courses for teachers' key competencies can enable the promotion of digital training programs for teachers, to realize international education, science education, reading education, environmental education, and exploration education.

2) Encourage teachers participating in this needs assessment project to consider the influence previous courses 
have had on key teaching competencies and the professional development of teachers in order to improve the modular courses thereby ensuring that it better satisfies the needs of all K-9 school teachers in Hsinchu.

3) Promote the modular courses on the basis of teacher evaluation mechanisms, such as professional development, professional development evaluation, and developmental teaching support systems to facilitate the development of future teacher empowerment learning and certification systems.

4) Integrate the resources of the course modules, including the HCED's annual education policies, courses offered in the Hsinchu Teacher Training Center, as well as opinions of HSECG teachers and NHUE teachers and consultants. Through the course modules, Hsinchu can realize its educational visions and practices for 2012-2014 and the HCED's policies for 2014.

5) Propose plans and recommendations for the future implementation of the modular courses.

\section{References}

Chang, C. J., \& Liu, H. M. (2011). Literature review of research on parent-child joint book reading in Taiwan. Bulletin of Educational Psychology, 43(S), 315-336. http://dx.doi.org/10.6251/BEP.20110704

Chao, J. Y. (2013). On the development of creativity and cooperation skills in indigenous elementary school students during a LEGO Mindstorms NXT course. Journal of Education Practice and Research, 26(1), $33-62$.

Chen, K. Y., Jian, Y. F., \& Ou, T. H. (2013). A study on the relationships among recreation involvement, place attachment, and environmentally responsible behavior: A case of SCUBA divers. Journal of Leisure and Recreation Industry Management, 6(2), 1-22. http://dx.doi.org/10.6213/JLRIM.2013.6(2)1

Chen, Q. L. (2009). To guide students' thinking process via reading. Learning Information, 26(2), 11-16.

Chen, Y. T., \& Chen, Y. C. (2008). The analysis of epistemologies about different background patriarchs in the context of parent-child book-reading interactions. Chinese Journal of Science Education, 16(3), 325-350.

Chou, J., \& Chiang, Y. C. (2013). Exploring the characteristics of quality environmental learning centers by the delphi technique Journal of Environmental Education Research, 9(2), 1-32.

Chou, Y. J., \& Chang, C. J. (2008). Effects of joint book reading on young children's narration of the mental states of story characters. Bulletin of Educational Psychology, 40(2), 261-281. http://dx.doi.org/10.6251/BEP.20080328

Ho, C. J. (2004). Reading, dialoguing, writing and cultural understanding: A reflection on a multicultural educational program. Kaohsiung Normal University Journal, 17, 1-20.

Hsinchu City Government. (2013). The project of enhancement and improvement of instructional quality in 12-year compulsory education in the 102th academic year. Retrieved from http://12basic.hc.edu.tw/doc/course/ct05.pdf

Hsinchu City Government. (2014). Hsinchu City is the first to be picked as one of the seven top smart cities globally other than the five municipalities. Retrieved from http://www.hccg.gov.tw/web/News?command=showDetail\&postId=254042

Intelligent City of Hsinchu of Information Service Network. (2014). The origin of the smart city. Retrieved from $\mathrm{http} / / /$ icity.hccg.gov.tw/index.aspx

Ji, Y. L. (2009). An action research of adventure education merging into ntegrative activity learning area in elementary schools (Master thesis, National Taitung University).

Lai, W. F. (2007). Listening to the marginalized voices: From narratives of "new Taiwanese children" to multicultural early childhood education. Curriculum \& Instruction Quarterly, 10(1), 65-81.

Lin, M. D. (2012). The talk on students' international learning from the perspective of international education policy in elementary and junior high schools. The Teachers' Chamber, 180, 4-9. Retrieved from http://web.tiec.tp.edu.tw/otiec/teacherland/catalog/upload_file/18003.pdf

Luo, S. C., \& Lin, S. W. (2012). The design and development of a scale for assessing learning strategy during scientific inquiry for elementary students. Chinese Journal of Science Education, 20(6), 515-538.

Ou, Z. Z. (2013). To promote reading education to enhance citizens' cultural literacy. Commercial Vocational Education, 130, 12-18.

Parnes, S. J., \& Meadow, A. (1959). Effects of "brainstorming" instructions on creative problem solving by 
trained and untrained subjects. Journal of Educational Psychology, 50(4), 171-176.

Ratner, N., \& Bruner, J. S. (1978). Games, social exchange and the acquisition of language. Journal of Child Language, 5, 391-401.

Shen, Y. S. (2010). Developing the indicators for the digital teaching abilities of primary and junior high school teachers (Master thesis, National Hsinchu University of Education, Hsinchu).

Vygotsky, L. S. (1962). Thought and language (E. Hanfmann \& G. Vakar, Trans.). In E. Hanfmann, \& G. Vakar (Eds.). Cambridge, MA: MIT Press.

Wang, C. M., \& li, C. Y. (2008). An experiment on psychological health of the elementary school students improved by experiential learning. Journal of Asia Association for Experiential Education, 2, 59-76.

Wei, X. T. (2001). Applications countries CPS mode of life science and technology. Living Technology Education, 34(10), 25-32.

Williams, D. R., \& Patterson, M. E. (1996). Environmental meaning and ecosystem management: Perspectives from environmental psychology and human geography. Society \& Natural Resources, 9(5), 507-521.

Wu, Q. J. (2010). The promotion of nationwide reading education-everybody reads. The Bi-Monthly Journal of Development and Evaluation, 34(1), 62-66.

Wu, S. F., Kuo, S. C., \& Chung, U. L. (2007). Student's experiences with experiential circle learning. Journal of Asia Association for Experiential Education, 5(1), 37-48.

Ye, J. Y. (2011). Unfavorable student learning difficulties and needs of science education-An learning disabilities Health Case. Annals of the Republic of China Institute of Special Education, 261-281.

Yeh, G. L., \& Tang, H. L. (2006). A study of the effects of values clarification approach for resources recycling education in the field of health and physical education of junior high schools. Chinese Journal of School Health, 48, 97-115.

\section{Copyrights}

Copyright for this article is retained by the author(s), with first publication rights granted to the journal.

This is an open-access article distributed under the terms and conditions of the Creative Commons Attribution license (http://creativecommons.org/licenses/by/3.0/). 